\title{
New types of toxin A-negative, toxin B-positive strains among clinical isolates of Clostridium difficile in Australia
}

\author{
Correspondence \\ Thomas V. Riley \\ triley@cyllene.uwa.edu.au
}

Received 4 February 2011

Accepted 7 March 2011

\author{
Briony Elliott, ${ }^{1}$ Michelle M. Squire, ${ }^{1}$ Sara Thean, ${ }^{2}$ Barbara J. Chang, ${ }^{1}$ \\ Jon S. Brazier, ${ }^{3}$ Maja Rupnik ${ }^{4}$ and Thomas V. Riley ${ }^{1,2}$ \\ ${ }^{1}$ Microbiology \& Immunology, The University of Western Australia, Nedlands 6009, Western \\ Australia, Australia \\ ${ }^{2}$ Division of Microbiology \& Infectious Diseases, PathWest Laboratory Medicine, Nedlands 6009, \\ Western Australia, Australia \\ ${ }^{3}$ Anaerobe Reference Unit, Cardiff, Wales, UK \\ ${ }^{4}$ Institute for Public Health, Maribor, Slovenia
}

\begin{abstract}
A total of 817 human clinical isolates of Clostridium difficile from all Australian states were screened for $A^{-} B^{+}$strains by toxin gene PCR assays. Nine $(1.1 \%)$ strains were confirmed to be $A^{-} B^{+}$by enzyme immunoassay for toxin production. Of these, six (66.7\%) were binary toxinpositive by PCR. Using PCR ribotyping and toxinotyping, the $\mathrm{A}^{-} \mathrm{B}^{+}$strains could be grouped into seven ribotypes and three toxinotypes. Only one of the ribotypes had been reported previously (017). The prevalence of ribotype 017 was low in this study with only two strains detected. Two new $A^{-} B^{+}$toxinotypes were also defined $(X X X, X X X I)$. Toxinotype $X X X$ had a toxin $B$ gene similar to that of toxinotype IV $\left(A^{+} B^{+}\right)$but with a novel cytopathic region. Toxinotype $X X X I$ was similar to other $\mathrm{A}^{-} \mathrm{B}^{+}$types $(\mathrm{X}, \mathrm{XVII})$, but had a larger deletion to the toxin $\mathrm{A}$ gene than in either of those types. The types of $A^{-} B^{+}$strains identified in this study differed markedly from those described in other regions.
\end{abstract}

\section{INTRODUCTION}

Clostridium difficile is the most frequently diagnosed cause of infectious nosocomial diarrhoea and pseudomembranous colitis. The characteristic diarrhoea and inflammation of $C$. difficile infection is toxin-mediated. Pathogenic strains typically produce two major toxins, toxin A (TcdA, an enterotoxin) and toxin B (TcdB, a cytotoxin), which are recognized as the major virulence factors. The genes for these toxins, together with three regulatory genes, are chromosomally located on the $19.6 \mathrm{~kb}$ pathogenicity locus (PaLoc) (Rupnik, 2008). Non-toxigenic strains lack this element (Cohen et al., 2000).

Strains with variations in the genes for toxin A and B $(t c d A$ and $t c d B$, respectively) often produce a third unrelated binary toxin (CDT) (Stubbs et al., 2000). This toxin is encoded on a separate region of the chromosome comprising the two components of CDT $(c d t A, c d t B)$ and a regulatory gene $(c d t R)$ (Carter et al., 2007). The role of binary toxin in disease is not well understood but CDTpositive strains are associated with more severe disease in

Abbreviations: ARU, Anaerobe Reference Unit; PaLoc, pathogenicity locus. humans and are found more commonly in animals (Barbut et al., 2005; Rupnik, 2007).

The majority of $C$. difficile strains produce both toxin A and $\mathrm{B}$ but a small number have deletions in $t c d A$ and produce only a functional toxin B (Voth \& Ballard, 2005). These strains were initially thought to be non-toxigenic as they were isolated from asymptomatic individuals and did not cause disease in a mouse model of infection (Borriello et al., 1992). Subsequently, clinically relevant toxin Anegative, toxin $\mathrm{B}$-positive $\left(\mathrm{A}^{-} \mathrm{B}^{+}\right)$strains have been well described in humans (Alfa et al., 2000; Drudy et al., 2007; Kuijper et al., 2001; Pituch et al., 2001; Sato et al., 2004) and animals (Thakur et al., 2010). There is also evidence that the prevalence of clinically significant $\mathrm{A}^{-} \mathrm{B}^{+}$strains may be increasing (Goorhuis et al., 2009).

Until recently, nearly all pathogenic $\mathrm{A}^{-} \mathrm{B}^{+}$strains were thought to possess a $1.8 \mathrm{~kb}$ deletion in the $3^{\prime}$ repeating region of $t c d A$, and classed as toxinotype VIII (Rupnik et al., 1998; Soehn et al., 1998). Only one other PaLoc variant had been described (a $5.9 \mathrm{~kb}$ deletion in the $3^{\prime} t c d A$ region, toxinotype $\mathrm{X}$ ), although this was isolated from an asymptomatic patient (Soehn et al., 1998). Recent reports from Asia have described $\mathrm{A}^{-} \mathrm{B}^{+} \mathrm{CDT}^{+}$strains with 
different PaLoc arrangements, suggesting that the molecular epidemiology of these strains may be different in this region (Rupnik et al., 2003).

Little is known about the molecular epidemiology of $\mathrm{A}^{-} \mathrm{B}^{+}$ C. difficile in Australia. This study examines the frequency and molecular diversity of $\mathrm{A}^{-} \mathrm{B}^{+}$strains among 817 recent Australian $C$. difficile clinical isolates of human origin. All $\mathrm{A}^{-} \mathrm{B}^{+}$strains were characterized by PCR toxin gene screening, PCR ribotyping and toxinotyping.

\section{METHODS}

Bacterial isolates. A total of 817 C. difficile human clinical strains isolated between 2005 and 2010 were included in this study. These were recovered from patients in all of Australia's states and territories, in hospitals, long-term care facilities and in the community. The identity of the isolates was confirmed using standard techniques (Bowman \& Riley, 1988; Brazier, 1998).

Detection of toxin genes by PCR. All isolates included in this study were screened for the presence of the toxin A and toxin B genes by PCR (Kato et al., 1991, 1998). Isolates were also screened for changes in the repeating region of $t c d A$ with the primer pair NK11-NK9 as described by Kato et al. (1998). Isolates that were PCR-positive for $t c d B$ and generated an approximately 1200 bp product with NK9NK11 were designated $\mathrm{A}^{+} \mathrm{B}^{+}$. Isolates that were PCR-positive for $t c d B$ but were PCR-negative or generated a truncated product with either primer pair for $t c d A$ were tested for TcdA and TcdB production as described below. The presence of both binary toxin genes, $c d t A$ and $c d t B$, was detected by PCR assay (Stubbs et al., 2000).

Toxin production. The production of both toxin A and toxin B was determined using the immunoassay Cdiff 2-AB stick (Operon). A cell culture cytotoxin assay using Vero cells was also used to confirm toxin $\mathrm{B}$ production and to characterize the cytopathic effect (Bowman \& Riley, 1988).

Detection of PaLoc accessory genes. The presence of the $t c d E$ gene (Braun et al., 1996) was confirmed by PCR, as was the presence of the $t c d C$ gene, which was also sequenced to detect any deletions (Spigaglia \& Mastrantonio, 2002).

PCR ribotyping. All $\mathrm{A}^{-} \mathrm{B}^{+}$isolates were typed by PCR ribotyping (Stubbs et al., 1999). Potentially novel ribotypes were referred to the
Anaerobe Reference Unit (ARU), Cardiff, UK, for confirmation. An $\mathrm{AU}$ (Australian) type number was used to identify the ribotype of a strain where a UK number had yet to be issued by the ARU.

Toxinotyping. Each strain was characterized by toxinotyping (Rupnik et al., 1997, 1998). Two fragments were used for toxinotyping, B1 and A3. New types were referred to the Institute for Public Health, Maribor, Slovenia, for analysis of the entire PaLoc by RFLP.

\section{RESULTS AND DISCUSSION}

Among the 817 isolates tested, 19 (2.3\%) had an abnormal PCR result for either $t c d A$ PCR assay. Nine $(47.4 \%)$ of these were confirmed as TcdA-negative by enzyme immunoassay. The remaining strains were identified as variant $\mathrm{A}^{+} \mathrm{B}^{+}$toxinotypes $(\mathrm{V}, \mathrm{VI})$ possessing deletions in $t c d A$ that did not abrogate toxin production. Of the nine $\mathrm{A}^{-} \mathrm{B}^{+}$strains, binary toxin genes were detected in six $(66.7 \%)$.

A 700 bp amplification product with the primer set NK11NK9 characteristic of toxinotype VIII strains was only seen in three Australian isolates (Table 1). Two of these were ribotype 017 , while the other belonged to a ribotype not reported previously. Both of the ribotype 017 strains were isolated in Eastern Australia in the state of Victoria. A total of seven $\mathrm{A}^{-} \mathrm{B}^{+}$ribotype groups were identified, six of which had not been reported to the ARU before (Fig. 1). Most of these ribotype groups contained only one isolate: the exception was AU 13, which contained two isolates.

Two new $\mathrm{A}^{-} \mathrm{B}^{+}$toxinotypes were identified in this study. The majority of Australian $\mathrm{A}^{-} \mathrm{B}^{+}$ribotypes belonged to toxinotype XXX. Most of these had very similar ribotyping profiles, differing by one to two bands. The $t c d B$ gene of this toxinotype had a new RFLP pattern for the B1 fragment (catalytic region) while the rest of $t c d B$ was similar to that of toxinotype IV $\left(\mathrm{A}^{+} \mathrm{B}^{+}\right)$. None of the PCR fragments covering the $t c d A$ gene could be amplified. The PaLoc accessory genes $t c d E$ and $t c d C$ were also negative in PCR assays. Only one human strain belonging to

Table 1. Characteristics of Australian C. difficile $\mathrm{A}^{-} \mathrm{B}^{+}$strains

\begin{tabular}{|c|c|c|c|c|c|c|c|}
\hline \multirow[t]{2}{*}{ Ribotype $^{*}$} & \multirow[t]{2}{*}{ No. of strains } & \multicolumn{2}{|c|}{$\operatorname{tcd} A \dagger$} & \multirow[t]{2}{*}{$c d t A / B$} & \multirow[t]{2}{*}{$\operatorname{tcdC}$} & \multirow[t]{2}{*}{$t c d E$} & \multirow[t]{2}{*}{ Toxinotyp } \\
\hline & & Non-rep. & Rep. & & & & \\
\hline UK 017 & 2 & + & $700 \mathrm{bp}$ & - & + & + & VIII \\
\hline AU 219 & 1 & + & 700 bp & - & + & + & VIII \\
\hline UK 291 & 1 & - & - & + & - & - & $\mathrm{XXX}$ \\
\hline AU 13 & 2 & - & - & + & - & - & $\mathrm{XXX}$ \\
\hline UK 280 & 1 & - & - & + & - & - & $\mathrm{XXX}$ \\
\hline UK 281 & 1 & - & - & + & - & - & $\mathrm{XXX}$ \\
\hline UK 237 & 1 & - & - & + & - & - & XXXI \\
\hline
\end{tabular}

${ }^{*} \mathrm{AU}$ (Australian) type is used where ARU has yet to assign UK ribotyping number.

$\dagger$ Non-rep., non-repeating fragment of $t c d A$; Rep., repeating fragment of $t c d A$. 


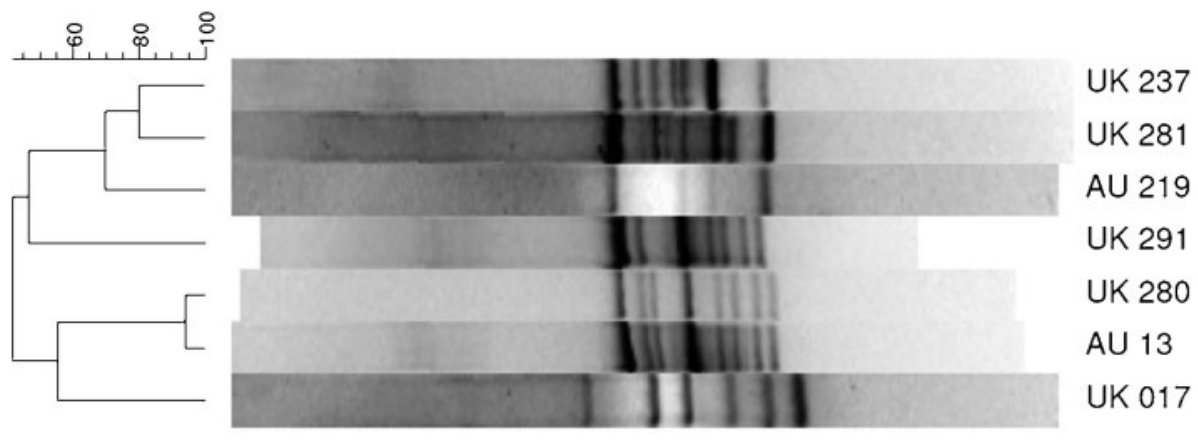

Fig. 1. Australian $C$. difficile $A^{-} B^{+} P C R$ ribotypes.

toxinotype XXXI was identified from a 94-year-old woman hospitalized in Western Australia. The same ribotype and toxinotype, however, are common animal isolates (unpublished data) in the same state. Toxinotype XXXI was similar to toxinotypes X and XVI, but lacked the A1 and PL3 fragments, suggesting an even larger deletion in $t c d A$ than is present in toxinotype $\mathrm{X}$. Both of the new toxinotypes displayed an abnormal cytopathic effect in vitro similar to that of the Clostridium sordellii TcsL rather than that of TcdB from non-variant $C$. difficile strains (Torres, 1991).

Previous typing studies of $\mathrm{A}^{-} \mathrm{B}^{+}$isolates from multiple countries have shown a high degree of similarity among strains (Johnson et al., 2003; van den Berg et al., 2004). One particular clindamycin-resistant strain of apparent clonal origin (toxinotype VIII, PCR ribotype 017) has dominated international typing studies of $\mathrm{A}^{-} \mathrm{B}^{+}$and been the cause of epidemics in Canada, the Netherlands, Ireland and Poland (Alfa et al., 2000; Drudy et al., 2007; Kuijper et al., 2001; Pituch et al., 2007). Although the frequency of $\mathrm{A}^{-} \mathrm{B}^{+}$strains in our collection was similar to that observed elsewhere (Brazier et al., 1999), they were surprisingly heterogeneous with only two strains belonging to ribotype 017 . The majority of Australian $\mathrm{A}^{-} \mathrm{B}^{+}$isolates were new, belonging to ribotypes and toxinotypes not previously reported. Unlike ribotype 017, all but one of the Australian ribotypes were binary toxin-positive and displayed a variant cytotoxicity due to changes in the cytopathic region of $t c d B$ resulting in changes to substrate specificity. These characteristics are also present in most $\mathrm{A}^{-} \mathrm{B}^{+}$toxinotypes other than VIII.

The epidemiology of $C$. difficile in the Asia-Pacific region differs from elsewhere. While a study of Asian isolates identified two new $\mathrm{A}^{-} \mathrm{B}^{+}$toxinotypes, the majority of $\mathrm{A}^{-} \mathrm{B}^{+}$strains were still ribotype 017 (Rupnik et al., 2003). A recent study of 75 isolates from Shanghai, however, identified $25 \mathrm{~A}^{-} \mathrm{B}^{+}$isolates of which only 14 belonged to ribotype 017, with the rest spread among three other ribotypes (Huang et al., 2009).

In the present study, we have described the prevalence and type of $\mathrm{A}^{-} \mathrm{B}^{+}$strains among $C$. difficile clinical isolates in Australia. We have also described two new $\mathrm{A}^{-} \mathrm{B}^{+}$ toxinotypes. Further studies are required to show whether these strains are found in other parts of the world, or are peculiar to the Australasian region.

\section{ACKNOWLEDGEMENTS}

We are grateful to the various diagnostic laboratories that contributed strains to this study.

\section{REFERENCES}

Alfa, M. J., Kabani, A., Lyerly, D., Moncrief, S., Neville, L. M., Al-Barrak, A., Harding, G. K., Dyck, B., Olekson, K. \& Embil, J. M. (2000). Characterization of a toxin A-negative, toxin B-positive strain of Clostridium difficile responsible for a nosocomial outbreak of Clostridium difficile-associated diarrhea. J Clin Microbiol 38, 2706-2714.

Barbut, F., Decré, D., Lalande, V., Burghoffer, B., Noussair, L., Gigandon, A., Espinasse, F., Raskine, L., Robert, J. \& other authors (2005). Clinical features of Clostridium difficile-associated diarrhoea due to binary toxin (actin-specific ADP-ribosyltransferase)-producing strains. J Med Microbiol 54, 181-185.

Borriello, S. P., Wren, B. W., Hyde, S., Seddon, S. V., Sibbons, P., Krishna, M. M., Tabaqchali, S., Manek, S. \& Price, A. B. (1992). Molecular, immunological, and biological characterization of a toxin A-negative, toxin B-positive strain of Clostridium difficile. Infect Immun 60, 4192-4199.

Bowman, R. A. \& Riley, T. V. (1988). Laboratory diagnosis of Clostridium difficile-associated diarrhoea. Eur J Clin Microbiol Infect Dis 7, 476-484.

Braun, V., Hundsberger, T., Leukel, P., Sauerborn, M. \& von EichelStreiber, C. (1996). Definition of the single integration site of the pathogenicity locus in Clostridium difficile. Gene 181, 29-38.

Brazier, J. S. (1998). The diagnosis of Clostridium difficile-associated disease. J Antimicrob Chemother 41 (Suppl. C), 29-40.

Brazier, J. S., Stubbs, S. L. \& Duerden, B. I. (1999). Prevalence of toxin A negative/B positive Clostridium difficile strains. J Hosp Infect 42, 248-249.

Carter, G. P., Lyras, D., Allen, D. L., Mackin, K. E., Howarth, P. M., O'Connor, J. R. \& Rood, J. I. (2007). Binary toxin production in Clostridium difficile is regulated by CdtR, a LytTR family response regulator. J Bacteriol 189, 7290-7301.

Cohen, S. H., Tang, Y. J. \& Silva, J., Jr (2000). Analysis of the pathogenicity locus in Clostridium difficile strains. J Infect Dis 181, 659-663. 
Drudy, D., Harnedy, N., Fanning, S., O’Mahony, R. \& Kyne, L. (2007). Isolation and characterisation of toxin A-negative, toxin B-positive Clostridium difficile in Dublin, Ireland. Clin Microbiol Infect 13, 298-304.

Goorhuis, A., Legaria, M. C., van den Berg, R. J., Harmanus, C., Klaassen, C. H., Brazier, J. S., Lumelsky, G. \& Kuijper, E. J. (2009). Application of multiple-locus variable-number tandem-repeat analysis to determine clonal spread of toxin A-negative Clostridium difficile in a general hospital in Buenos Aires, Argentina. Clin Microbiol Infect 15, 1080-1086.

Huang, H., Fang, H., Weintraub, A. \& Nord, C. E. (2009). Distinct ribotypes and rates of antimicrobial drug resistance in Clostridium difficile from Shanghai and Stockholm. Clin Microbiol Infect 15, 11701173 .

Johnson, S., Sambol, S. P., Brazier, J. S., Delmée, M., Avesani, V., Merrigan, M. M. \& Gerding, D. N. (2003). International typing study of toxin A-negative, toxin B-positive Clostridium difficile variants. J Clin Microbiol 41, 1543-1547.

Kato, N., Ou, C.-Y., Kato, H., Bartley, S. L., Brown, V. K., Dowell, V. R., Jr \& Ueno, K. (1991). Identification of toxigenic Clostridium difficile by the polymerase chain reaction. J Clin Microbiol 29, 33-37.

Kato, H., Kato, N., Watanabe, K., Iwai, N., Nakamura, H., Yamamoto, T., Suzuki, K., Kim, S.-M., Chong, Y. \& Wasito, E. B. (1998). Identification of toxin A-negative, toxin B-positive Clostridium difficile by PCR. J Clin Microbiol 36, 2178-2182.

Kuijper, E. J., de Weerdt, J., Kato, H., Kato, N., van Dam, A. P., van der Vorm, E. R., Weel, J., van Rheenen, C. \& Dankert, J. (2001). Nosocomial outbreak of Clostridium difficile-associated diarrhoea due to a clindamycin-resistant enterotoxin A-negative strain. Eur J Clin Microbiol Infect Dis 20, 528-534.

Pituch, H., van den Braak, N., van Leeuwen, W., van Belkum, A., Martirosian, G., Obuch-Woszczatyński, P., kuczak, M. \& MeiselMikołajczyk, F. (2001). Clonal dissemination of a toxin-A-negative/ toxin-B-positive Clostridium difficile strain from patients with antibioticassociated diarrhea in Poland. Clin Microbiol Infect 7, 442-446.

Pituch, H., van Leeuwen, W., Maquelin, K., Wultańska, D., ObuchWoszczatyński, P., Nurzyńska, G., Kato, H., Reijans, M., MeiselMikołajczyk, F. \& other authors (2007). Toxin profiles and resistances to macrolides and newer fluoroquinolones as epidemicity determinants of clinical isolates of Clostridium difficile from Warsaw, Poland. J Clin Microbiol 45, 1607-1610.

Rupnik, M. (2007). Is Clostridium difficile-associated infection a potentially zoonotic and foodborne disease? Clin Microbiol Infect 13, 457-459.

Rupnik, M. (2008). Heterogeneity of large clostridial toxins: importance of Clostridium difficile toxinotypes. FEMS Microbiol Rev 32, 541-555.
Rupnik, M., Braun, V., Soehn, F., Janc, M., Hofstetter, M., Laufenberg-Feldmann, R. \& von Eichel-Streiber, C. (1997). Characterization of polymorphisms in the toxin A and B genes of Clostridium difficile. FEMS Microbiol Lett 148, 197-202.

Rupnik, M., Avesani, V., Janc, M., von Eichel-Streiber, C. \& Delmée, M. (1998). A novel toxinotyping scheme and correlation of toxinotypes with serogroups of Clostridium difficile isolates. J Clin Microbiol 36, 2240-2247.

Rupnik, M., Kato, N., Grabnar, M. \& Kato, H. (2003). New types of toxin A-negative, toxin B-positive strains among Clostridium difficile isolates from Asia. J Clin Microbiol 41, 1118-1125.

Sato, H., Kato, H., Koiwai, K. \& Sakai, C. (2004). [A nosocomial outbreak of diarrhea caused by toxin A-negative, toxin B-positive Clostridium difficile in a cancer center hospital]. Kansenshogaku Zasshi 78, 312-319 (in Japanese)

Soehn, F., Wagenknecht-Wiesner, A., Leukel, P., Kohl, M., Weidmann, M., von Eichel-Streiber, C. \& Braun, V. (1998). Genetic rearrangements in the pathogenicity locus of Clostridium difficile strain 8864 - implications for transcription, expression and enzymatic activity of toxins A and B. Mol Gen Genet 258, 222-232.

Spigaglia, P. \& Mastrantonio, P. (2002). Molecular analysis of the pathogenicity locus and polymorphism in the putative negative regulator of toxin production (TcdC) among Clostridium difficile clinical isolates. J Clin Microbiol 40, 3470-3475.

Stubbs, S. L. J., Brazier, J. S., O’Neill, G. L. \& Duerden, B. I. (1999). PCR targeted to the 16S-23S rRNA gene intergenic spacer region of Clostridium difficile and construction of a library consisting of 116 different PCR ribotypes. J Clin Microbiol 37, 461-463.

Stubbs, S., Rupnik, M., Gibert, M., Brazier, J., Duerden, B. \& Popoff, M. (2000). Production of actin-specific ADP-ribosyltransferase (binary toxin) by strains of Clostridium difficile. FEMS Microbiol Lett 186, 307312.

Thakur, S., Putnam, M., Fry, P. R., Abley, M. \& Gebreyes, W. A. (2010). Prevalence of antimicrobial resistance and association with toxin genes in Clostridium difficile in commercial swine. Am J Vet Res 71, 1189-1194.

Torres, J. F. (1991). Purification and characterisation of toxin B from a strain of Clostridium difficile that does not produce toxin A. J Med Microbiol 35, 40-44.

van den Berg, R. J., Claas, E. C. J., Oyib, D. H., Klaassen, C. H. W., Dijkshoorn, L., Brazier, J. S. \& Kuijper, E. J. (2004). Characterization of toxin A-negative, toxin B-positive Clostridium difficile isolates from outbreaks in different countries by amplified fragment length polymorphism and PCR ribotyping. J Clin Microbiol 42, 1035-1041.

Voth, D. E. \& Ballard, J. D. (2005). Clostridium difficile toxins: mechanism of action and role in disease. Clin Microbiol Rev 18, 247-263. 